\title{
Extra Lessons and Academic Achievement of Learners among Urban Day High Density Secondary School Learners
}

Richard Bukaliya: Zimbabwe Open University, Mashonaland East Regional Campus, Zimbabwe.

\begin{abstract}
This multiple case study was an analysis of the perceptions of teachers, parents, school inspectors and learners towards the role of extra lessons on the academic achievement of learners in three secondary schools in Chegutu Urban, Zimbabwe. The study was guided by the Incentive Theory of Motivation developed by Young (1936), which postulates that there are many reasons that drive people towards doing certain things. The study adopted the interpretivist paradigm that hinges on the premise that social meaning is created by interacting with various participants affected by a phenomenon it was rooted in the qualitative approach. Interviews, focus group discussions and document analysis were used to generate data. The results of the study show that extra lessons were used to improve learners academic achievement. Extra lessons came in as a form of remediation for learners who failed to grasp concepts during the formal learning school hours. The lessons also enhanced slow learners" achievement and sustained gifted learners' academic levels through extension work. They helped learners in getting admission into institutions of higher learning. Due to the positive academic role of the extra lessons, it was recommended that there is need to take extra lessons seriously. Extra lessons could be used to make up for the time limitations in the urban day high density secondary schools where there is double sessioning. However, there is need to monitor the learners as they go away for the extra lessons to find out if, indeed, they are benefitting from them. Learners, who stand to benefit from the extra lessons, need to take into account that they should not wait for teachers to do virtually everything for them but rather use extra lessons for guidance on how they go about certain activities. Learners should do most of the activities through learner centred approaches, under the guidance of the extra lessons teachers. There is need for a legal frame work to operationalise the extra lessons. The Government of Zimbabwe could have extra lessons as a revenue base through which teachers practising extra lessons could have their extra remuneration from extra lessons taxed.
\end{abstract}

Key words: Extra lessons, Academic achievement, Urban day, High density, Secondary school, Learners.

\section{Introduction}

With competition rife among learners for better academic results, extra lessons, also referred to as supplementary education (Bray, 2011), have become very popular to the extent that they have been an activity that has been incorporated in education sub-systems in most countries, globally, as learners take to the activity on a very large scale (Baker, Akiba, Le Tendre, \& Wiseman, 2011; Bray, 2015). Most modern societies with well pronounced formal education systems have accepted and adopted the use of extra lessons that have come in different forms, in different countries. This is against the belief that the extra lessons can help learners in various ways. In Canada, for example, Davies and Aurini (2016) describe the exponential growth of the extra lessons as very significant and have depicted the growth as that of sprouting from "push cart" business to a thriving cottage industry. In Zimbabwe, initiatives for good quality education have seen the mushrooming of private schools in most parts of the country as demand for the highly regarded prestigious system of education becomes the envy of many, on one

Vol. 2, No.3, pp. 136-150

2019

Funding: This study received no specific

financial support.

Received: 2 August 2019

Revised: 9 September 2019

Accepted: 11 October 2019

(C) 2019 by the authors; licensee Academic

Publishing Group 


\section{Academia}

International Journal of Educational Studies

Vol. 2, No.3, pp. 136-150

2019

DOI: $10.53935 / 2641-533 x . v 2 i 3.116$

Funding: This study received no specific

financial support.

Article History:

Received: 2 August 2019

Revised: 9 September 2019

Accepted: 11 October 2019

Published: 8 November 2019

(C) 2019 by the authors; licensee Academic

Publishing Group hand. Even rural areas have seen the sprouting of private and highly elite schools. On the other, the idea and attempt aimed at supplementing and complementing what has been learnt in the formal school classroom through extra lessons has received a lot of attention from different stakeholders who include parents, learners, teachers, among others, who have seen it necessary to be involved in the extra lessons (Bewu, 2013). This has been amidst dissenting views on the need for these extra lessons from other dissatisfied educational stakeholders especially the Ministry of Primary and Secondary Education (MOPSE) (Tokwe, 2010). The practice has become so intense in the Zimbabwean primary and secondary schools so much that people have started to debate on what role these extra lessons may be playing in the mainstream Zimbabwean education system (Tokwe, 2010).

What then became a talking point was that almost all learners of different abilities and educators of all forms of qualification, reputation and from different types of schools, whether public or private, and regardless of school location or status, went in for extra lessons. For example, educators and learners from the affluent schools in Zimbabwe, such as the former Group A institutions, that is, those schools which were preserved for the elite white Rhodesians during the colonial era, and the wealthy and wellresourced private and church controlled and owned boarding schools, also turned to the use of the extra lessons (Jinga \& Ganga, 2012). The much admired boarding schools and other high fee paying schools with the better share of qualified teachers made sure that they arranged vacation schools to offer extra lessons. Practices such as these have led to the investigation of the stakeholders` perceptions of the role of extra lessons in the education system in Zimbabwe.

\subsection{Statement of the Problem}

Originally, extra lessons were meant for reinforcement of concepts already covered in formal school classrooms and giving "more of the same" Silova and Bray (2006). However, currently, the situation as regards the practice of extra lessons appears to have taken a sudden shift from the initial purpose. Learners of different ability levels and teachers, be they qualified, reputable or not, are now seen to be taking part in extra lessons. The practice is now a free for all undertaking regardless of one`s ability or reputation. An analysis of the perceptions of teachers, parents, school inspectors and learners towards the role of extra lessons on the academic achievement of learners is, therefore, necessary.

\subsection{Research Questions}

The study aimed at addressing the following questions which guided the study:

1. How have extra lessons been of academic benefit to urban day secondary school learners?

2. Why have extra lessons attracted a lot of attention among learners in the urban day secondary schools?

3. How have extra lessons been used by urban day secondary school learners to prop up their academic achievement?

4. What have been the spill over academic related benefits of extra lessons for the urban day secondary school learners?

\subsection{The Theory Guiding the Study}

This study was guided by the Incentive Theory of Motivation, developed by Young (1936) which postulates that there are many reasons that drive people towards doing certain things. According to the theory, people and animals act in the manner they do because of the prospect of either an external or internal reward or incentive (Cherry, 2016). According to Bernstein (2011) the incentive theory assumes that individuals are enticed towards behaviours and actions that offer incentives that are positive and pulled away from those actions and behaviours that are in a way negative. Thus, Bernstein (2011) asserts that different people would normally behave differently in given situations based on the incentives available and the value placed on the expected or existing incentives at any one given time.

According to (Hockenbury \& Hockenbury, 2003), the incentives theory propounds that for action to take place, it is a result of a pull factor of external goals. These pull factors are inclusive of rewards, money, recognition and in the learning situation, good grades. Cherry (2016) posits that the incentive theory of motivation can be likened to operant conditioning discovered by Skinner (1950), in which behaviour is performed in order to gain reinforcement or for the avoidance of punishment. The argument, therefore, arises that learners would take to extra lessons to avoid the wrath of teachers in the 
classrooms and, hence, prepare for formal lessons, outside the formal school situation. The incentive theory premises that actions or behaviours are taken or exhibited specifically for the attainment of rewards. Cherry (2016), asserts that in a school situation, gaining esteem and attaining accolades are some of the rewards expected by learners from parents, peers and teachers. These rewards motivate learners towards certain behaviours and actions. A further assumption of the theory is that one can be motivated by things that he/she could have avoided especially when found to be unpleasant or undesirable at law. This then may help answer the question why learners take part in extra lessons.

Young (1936), articulates the following implications of the incentive theory:

- Incentives are likely to lead individuals engage in certain behaviours or actions. Thus if there is real or imagined belief about an incentive, individuals will take part in that activity, for example, extra lessons.

- The potency or efficacy of the reward or incentive provides the impetus to take part in an activity or behave in a certain way. People are therefore, obliged to act and behave positively where perceived rewards are naturally high and also very attractive. People can stop performing certain actions and behaving in a given way where rewards or incentives are rated lowly.

- The extent to which rewards or incentives are achievable provides a motivating effect to an individual. For that reasons, an individual could stop behaving in a given way if they discover that an incentive or reward is not achievable or attainable.

\subsection{Related Studies on Extra Lessons}

There have been mixed feelings about the efficacy of extra lessons in aiding the academic achievement of learners (Silova \& Bray, 2006). Originally, as argued by Bray (2009) and Tokwe (2010), extra lessons were a remediation strategy. Engaging in extra lessons has very positive objectives (Bray, 2009; Hallak \& Poisson, 2007; Tokwe, 2010). These include improving student learning and making better use of out-of-school time. In some cases, competition for the chance to make it into elite schools among learners has driven learners into attending extra lessons (Hallak \& Poisson, 2007). The current debate around extra lessons hinges on whether they are potent in the improvement of academic achievement or whether they are undermining education and development. While some scholars (Bray, 2005; Russell, 2002; Southgate, 2009), would like to believe that extra lessons have the potency to improve academic achievement some feel extra lessons have brought about inefficiencies in the mainstream (Baker \& Le Tendre, 2005; Cheo \& Quah, 2005). Teachers have been blamed for manipulating the mainstream by slackening their teaching to create opportunities for extra lessons (Lee, 2002; Mogari, Coetzee, \& Maritz, 2009).

Extra lessons were used mainly to boost learners`grades in the different subjects they were enrolled in Bray (2009). Learners who had received private lessons had double the chance of attaining higher grades than their counterparts, who had not received private lessons in the parallel system (Hamid, 2009). Extensive use of extra lessons paved the way for better performance in school work in Japan and indeed elsewhere especially in selected school subjects (Bray, 2009; Howrie, 1999; Mogari et al., 2009). There were positive effects of extra lessons on subjects such as Mathematics Jacob and Lefgren (2002). In the Republic of Korea, a study found a positive correlation between financial expenditures and academic performance (Sohn, Donghwan, Sunhwa, \& Tae, 2010). Those who spent more on their children`s education through extra lessons were mostly to benefit more on their investment (Sohn et al., 2010). A survey by Silova and Bray (2006) in Azerbaijan, Georgia, Mongolia and Ukraine, established that $60 \%$ of the respondents in Azerbaijan and over 50\% of the respondents in Georgia indicated that extra lessons were the only way to get high quality education.

Tertiary institutions have tended to pitch their entrance requirements significantly high and hence the desire to meet those requirements by a good number of learners (Bray, 2001; Moloi, 2001; Reddy, Berkowitz, \& Mji, 2005). Over $70 \%$ of the students who had enrolled in universities in Azerbaijan, Georgia, Mongolia and Lithuania indicated that they had undergone extra lessons in their final year in secondary school (Silova \& Bray, 2006). This could be indicative of the need for higher grades that were being demanded by universities in the different countries. In Pakistan, there was a significant positive effect of extra lessons on the academic achievement of secondary school learners in mathematics (Suleman \& Hussain, 2013). In their experimental study, Suleman and Hussain (2013) 


\section{Academia}

International Journal of Educational Studies

Vol. 2, No.3, pp. 136-150

2019

DOI: $10.53935 / 2641-533 x . v 2 i 3.116$

Funding: This study received no specific

financial support.

Article History:

Received: 2 August 2019

Revised: 9 September 2019

Accepted: 11 October 2019

Published: 8 November 2019

(C) 2019 by the authors; licensee Academic

Publishing Group established that the experimental group performed better than the control group. Similarly, an experiment on 904 pupils in Luxembourg, most of the respondents received tutoring in Mathematics and results suggested that private tutoring was effective in promoting academic performance (Mischo \& Ludwig, 2002). A study in Hong Kong by Bray (2013), revealed that private tutoring had academic benefits for the learners because it helped them improve their examination grades and helped boost confidence in the examinations. Private tutoring also assisted them in their revision skills as well as learning strategies, both of which contributed to academic achievement.

However, it has also been established that extra lessons are not always effective in raising academic achievement (Baker \& Le Tendre, 2005; Cheo \& Quah, 2005; Ireson \& Rushforth, 2005) and in some schools, learners commonly skip classes or sleep through lessons because they are tired after excessive external study. This means that the activities, such as extra lessons, can make regular schooling less efficient and lower the educational attainment of learners (Bray \& Lykins, 2012). Too much work for the children makes them to get tired and do not benefit from the extra lessons. In India, Yasmeen (2009) established that as a result of attending extra lessons, classroom attention tended to dwindle and the learners who were involved in the extra lessons created disciplinary problems. Yasmeen (2009) and Cheo and Quah (2005) conclude that the old adage, "the more the better" in terms of extra lessons does not match reality, and that diminishing returns set in rapidly when "over-investment in the child" takes place.

Some studies have also shown that there was an insignificant relationship between prior achievement and private tutoring among youths (Byun \& Park, 2012; Smyth, 2009). In Ireland, Smyth (2009) revealed that the take up of extra lessons did not yield any significant academic advantage in terms of grades especially for learners in upper secondary.

The incidence and impact of extra lessons tuition have often not been studied systematically in Africa Paviot, Heinshohn, and Korkman (2008). In their study, carried out in African nations of Kenya, Malawi, Mauritius, Zambia and Zanzibar, Paviot et al. (2008), established a mixed association between extra tuition and student academic achievement. While in some countries (e.g. Mauritius) there was a positive association, in others, (e.g. Zanzibar), there was a negative relationship between achievement and attending extra tutorials.

Dang and Rogers (2008) carried out a content analysis whose results indicate that there were mixed reactions to the effects of extra lessons. There was, however, a general agreement among some researchers in the different countries that private tutoring improved grades of students at almost all levels of education. For example, studies by Buchmann (2002) in Kenya,(Dang, 2007b) in Vietnam and Jacob and Lefgren (2004) in Japan indicated that students" grades improved after attending extra lessons. However, the same desk research by Dang and Rogers (2008) established a negative impact of private tutoring in some countries (e.g in Singapore and Korea). For example, Cheo and Quah (2005) in Singapore carried out a study on Grade 8 learners and established that the more time spent on private lessons, the more the negative impact on student academic achievement. Lee and Lee (2004), in Korea, investigated the effects of pre-class private lessons on middle and high school learners and established that the programme had no short or long term effects on the learner"s performance. These notable contradictions from among different regions of the world point to the view that extra lessons could be effective in some regions while being ineffective in others.

Private lessons, through a remedial education programme in Indian primary schools, increased the average scores in a test for learners who had been involved in the treatment group (Banerjee, Cole, Duflo, \& Linden, 2007). However, an interesting point to note from the study is that after a year of completion of the programme, initial gains of the programme decreased. The study concluded that the more time spent on extra lessons, the less the benefits. These results replicate those by Yasmeen (2009) and Cheo and Quah (2005) as earlier on revealed and seem to submit to the old adage "all work and no play makes John a dull boy".

Male students who attended individual tutoring gained an average of 0.7 of the GCSE grade, there was no significant benefit for girls who attended private tutoring in the same subject. This, therefore, showed that tutoring has different effects based on gender in terms of performance Ireson and Rushforth (2005). 
Other studies (Cheo \& Quah, 2005; Ha \& Harpham, 2005) have shown that private tutoring or individual tutoring has no positive impact on academic achievement of learners. A study by Suryadarma, Suryahadi, Sumarto, and Rogerset (2006), on improving student"s performance in primary schools in Indonesia, shows that private tutoring had no impact on Mathematics and dictation scores of Grade 4 learners. Carrying out a study in Singapore on Grade 8 learners, Cheo and Quah (2005) established that time spent on private tutorials with the Grade 8 learners impacted negatively on their academic attainment. The same findings were established by Ha and Harpham (2005) in Vietnam in a study on extra classes and their outcomes in primary schools.

A study in Kenya by Mboi and Nyambedha (2013) investigated the implications of extra tuition on primary school learners` social life. The cross sectional survey undertaken on 401 learners and 10 teachers generally made conclusions that that learners took part in extra tuition because they saw extra lessons as being beneficial in propping up their academic performance. Despite the main thrust of the paper being on the social implications of extra tuition, the study by Mboi and Nyambedha (2013) established that $30.6 \%$ of learners were of the opinion that they were interested in extra tuition because it made them improve their academic grades, while $24.4 \%$ indicated that extra tuition made them pass examinations, which enabled them to progress to the next grade level. In the same study, learners indicated that their teachers wanted them to pass their examinations in order to compete with other schools for positions. However, a minority of $0.3 \%$ indicated that extra tuition helped them get more clarification on issues in different subjects, unlike in the formal class. This was because teachers and learners had a lot of time to deliberate on tasks as teachers had more time to respond to learners` questions.

In a national survey involving thirteen countries worldwide, Baker, Akiba, Le Tendre, and Wiseman (2001) established that extra lessons in nations where there was a clear positive relationship between attendance in extra lessons and academic performance, extra lessons were adopted as an enrichment strategy for those lagging behind in different subjects. In the same study, it was found out that where the relationship between the two variables was negative, extra lessons were purely used as a remedial strategy. The same study established that, generally, these extra lessons were aimed at improving performance in the school. In some cases, though formal schools provided extensive learning programmes, in several nations surveyed, many families found it appropriate to enroll the children for extra lessons. Baker et al. (2011), further established that extra lessons were commonly used by low performing mathematics learners who felt their low performance could be remedied more than high mathematics performers who did not attend the extra lessons at all.

Nath (2016) carried out a study in Bangladesh and found out that stakeholders, such as mothers groups, that were involved as participants in focus group discussions concluded that private supplementary tutoring helped learners to do well in class. In the same study by Nath (2016), teachers felt that supplementary tutoring helped improve the quality of education. The participants in the study by Nath (2016) argued that what the learners failed to understand from the formal class, they got help from the tutor during private lessons as these tutors were friendlier than their teachers in the formal system. The study established that there was a positive correction between student performance and attending supplementary tutoring. In Trinidad and Tobago primary schools, studies reveal that tutoring produced high success rates that were measured in terms of how many graduates were placed in the high schools, which they had indicated as their first choice (Barrow \& Lochan, 2012). In Canada, over $50 \%$ of the parents in that country indicated that they would hire tutors if they could afford given a situation whereby extra lessons were being offered through ,shadow education” mostly meant for homework support and test preparation. According to the review paper, extra lessons were aimed at assisting learners pass impending tests and improve their course grades (Davies \& Aurini, 2016).

\section{Research Methodology and Methods}

The current study adopted the interpretivist research paradigm that hinges on the premise that social meaning is created during interaction with various participants affected by a phenomenon thus different participants, in the case of the present study, teachers, parents, learners and school inspectors, understand socially constructed reality differently (Dina, 2012; Hessie-Biber \& Leavy, 2006). From this philosophical perspective, this study was guided by the belief that interpretation of interactions and 
social meaning of a phenomenon was based on what people, the teachers, school inspectors, parents and learners, assign to their interaction of the phenomenon (Creswell, 2012), in this case, extra lessons. The study was rooted in the qualitative research approach that is aimed at the construction of a complex and holistic picture, informed by words, and through reporting very detailed beliefs and views of participants, and conducted in their natural and everyday settings (Creswell, 2012; Flick, 2011; Neuman, 2014). The study employed the multiple case study approach that paved way for the researcher to analyse findings both within each setting and across the given three schools (Baxter \& Jack, 2008). Thus, data were generated from three sites which are secondary schools located in the high density residential areas of Chegutu Urban. Interviews, focus group discussions and document analysis were used to generate data from the participants whose anonymity was guaranteed through the use pseudonyms.

\section{Study Participants}

Twenty-three participants were purposively selected. These consisted 8 teachers, 6 learners, 6 parents and 3 school inspectors selected through critical case sampling in which the researcher used own judgment to choose participants into the study (Brink, 2006; Johnson \& Christensen, 2012). Only those stakeholders who were involved in extra lessons and directly affected such as school inspectors and yielded the most important data that had the greatest impact and effect on the development of knowledge of extra lessons made it into the sample.

\section{Presentation and Discussion of Results}

\subsection{Improvement of Learners 'Academic Achievement}

One of the main findings from the data is that extra lessons are being used by learners in urban day high density secondary schools to improve their academic achievement. As depicted in the interview excerpts, participants extolled the positive role played by extra lessons in propping learner academic achievement. This is in line with the assumptions of the Incentives Theory which assumes that for action to take place, it is a result of a pull factor of external goals, which in the teaching and learning situation, could include good grades (Hockenbury \& Hockenbury, 2003). For example, according to one of the learners, Peter (not his real name), extra lessons assisted him in passing as he had improved more as compared to what was obtaining previously The learner had this to say:

As previously explained I did not understand mathematics, in fact I wasn"t good at mathematics. So, when I went for extra lessons, I discovered I was now picking up. For example, on matrices, at school I didn"t know them but when I came for extra lessons, then at school I was happy since I was able to raise my hand in class while understanding the topics I didn"t know or understand.

The sentence "I did not understand mathematics", shows Peter was bad at Mathematics. A further remark "I wasn't good" demonstrates he was doing well in Mathematics. However, after attending extra lessons, there is notable change in his performance in the learning area. This is signified by the phrase "I was now picking up" and "I was able to raise my hand in class". This shows it was only after attending extra lessons that he started to perform well. His understanding of mathematical concepts such as matrices improved to the extent that he was now participating in class unlike previously when he was not doing well.

Another learner participant, Moxon (not his real name), concurred with the views proffered by his colleague.

His remarks are presented in the following excerpt:

As for me extra lessons assisted me in that before I wrote I was someone who was not understanding mathematics a lot. So when I went for extra lessons I managed to get a lot of time because I am someone who takes time to grasp mathematical concepts. So I got a lot of time to ask where I did not understand, from the lessons teacher, because in the formal class we were more than 50. In the extra lessons class, we could be 15 . So, one can get a lot of time to get explanations on those issues that he or she did not understand. 
The phrase "not understanding mathematics a lot" shows that Moxon had some idea of Mathematics but for him, extra lessons assisted him because of availing a lot of time for him understand the subject as reflected in the phrase "I managed to get a lot of time". For someone who required more time, extra lessons gave him the opportunity to understand. In the phrase "am someone who takes time to grasp mathematical concepts", the learner shows that extra lessons provide adequate time to those who are not capable of understanding concepts in the formal classroom situation. As depicted in "one can get a lot of time to get explanations on those issues that he or she did not understand", one gets the feeling that extra lessons give learners a lot of time to ask questions and clarifications where they do not understand. The present findings resonate with those by Mboi and Nyambedha (2013) in Kenya, which show that extra tuition helped learners get more clarification on issues in different subjects unlike in the formal class. This was made possible due to the availability of time for the learners among other factors.

In an attempt to cross validate the findings, the researcher got access to the Moxon`s Mathematics extra lessons exercise books and the ones he used in the formal school. There was tremendous achievement in most topics covered in both exercise books. Concepts such as "transformation, quadratic equations and algebraic formulae" were poorly done at first in the school exercise books and later dates showed that these were done during extra lessons and were then well done in end of term examinations at the schools. This is seen in the qualitative comments by the teacher who indicated Very good, Good and Excellent in some of the exercises that were marked.

Devine`s views are in agreement with those proffered by his two learner colleagues. This is captured in the following excerpt:

As for me extra lessons assisted me in mathematics and English, when I did not attend extra lessons, mathematics was difficult. I didn"t pass with good grades. I used to obtain $50 \%$ but now I can go as far as $70 \%$ because when I am at school, in the normal class, some learners are fast at grasping concepts. As for me those concepts I am taught at school, if I don"t grasp them, I take those for extra lessons and they are revised and I grasp them fairly well, that"s what I did in most of the subjects I did not understand. So, I discovered that the extra lessons were very helpful.

From what Devine (not his real name) says one gets a feeling that that extra lessons have made mathematics fairly easy to understand. The phrase mathematics was difficult implies that the subject is now easy. I didn't pass with good grades also shows that he is now passing with goods grades. Evidence of improvement is also shown in the quantitative assessment where the learner used to get $50 \%$ but now he is getting $70 \%$. The sentence I grasp them fairly well also bears testimony to the idea that extra lessons are making the learner improve in mathematics and other subjects.

The same sentiments are echoed by Cecil (not his real name), another learner, in the following excerpt: I think the extra lessons assisted me because there are some subjects I did not understand but after going for extra lessons, the teacher gives you time to explain but the teachers in the formal school are fast to an extent that you wouldn"t understand what they would have said. Also, you would be crowded in a single classroom but when having extra lessons, you are given the opportunity to get issues explained and you can also ask. Therefore, I see those extra lessons helping a lot.

From the phrase "assisted me because there are some subjects I did not understand", one gets a feeling that there is some change in the academic of the learner after attending extra lessons. The phrase "extra lessons helping a lot" is clear indication of the benefit derived by the learner from the extra lessons. The issue of time continues to come out in all responses by participants as indicated in the phrase "teacher gives you time to explain". This is unlike in the formal school and that opportunity makes learners understand better and this translates to better academic achievement. As teachers in the mainstream felt constrained in terms of time, they rush over the teaching and learning process in order to cover more material in the syllabus and this was to the disadvantage of the learners unlike what obtains during extra lessons. This is seen in the phrase "you are given the opportunity to get issues explained".

Vol. 2, No.3, pp. 136-150

2019

Funding: This study received no specific

financial support.

Revised: 9 September 2019

Accepted: 11 October 2019

(c) 2019 by the authors; licensee Academic

Publishing Group 
In support of the learner participants, Mr. James (not his real name), one of the teacher participants, provides further insights into the role of extra lessons on the learner academic achievement by saying:

There is a notable difference between those who are attending and those not attending. Those attending extra lessons, at least they are able to obtain higher grades at the end as compared to those who would not have managed to attend the extra lessons due to economic problems. They are not getting close attention due to overwhelming numbers in a classroom situation. At the same time, some fear to be laughed at by others when they ask questions and this is not the case during extra lessons as numbers are few and based on ability to pay.

From the excerpt, it shows that performance differs between those attending and those not undertaking the extra lessons through the use of the words notable difference between those who are attending and those not attending. This is further highlighted in the phrase obtain higher grades at the end as compared to those who would not. Reasons for better performance for those attend are advanced in the excerpt. These are inability to ask in the formal class as well as being overcrowded. Not many learners are able to attend extra lessons as indicated by the phrase numbers are few. Due to the inability to pay by some learners, Bray (2003) has argued that there is perpetuation of the of the learners`academic gaps as those who cannot pay lag behind academically.

Ms. Ndumo (not her real name), a parent participant also weighed by remarking that extra lessons assisted in improving the academic achievement of her child (Nath, 2016). When asked to elaborate, she said, "There is a positive change. Last year, he wasn't attending extra lessons and he wasn't getting a book price but this year when he was attending extra lessons, he got a book price in Chemistry." The phrase positive change shows her son was now doing better. Further testimony to the positive role of extra lessons can be identified in the phrase "got a book price in Chemistry" which was unlike before the child attended extra lessons. To substantiate these claims, exercise books for the learner were perused. The child had made progress in those subjects in which extra lessons were being sought. Both the quantitative and qualitative remarks in the learner's exercise books for both the formal and extra lessons bore testimony to the fact that there was drastic improvement in the learner's academic achievement. The textbook prizes won by the learner were also presented as testimony to the good work that the extra lessons teachers were undertaking. The inscription on the first page of the textbooks was "Presented to (Name of Learner) for academic excellence in Chemistry". This was signed for by the school deputy head and date stamped. Prior to the extra lessons, the learner had not won any book prize at school. This is one of the accolades assumed in the Incentives Theory Cherry (2016). However, there was need to verify whether or not the book prize had been in deed awarded by the school.

The findings of this present study corroborate those of some studies. For example, Suleman and Hussain (2013) in Pakistan, established that here was a significant positive effect of private tuition on the academic achievement of secondary school learners, though in Mathematics. In that study, Suleman and Hussain (2013) established that learners who attended extra lessons performed better than those who did not take extra lessons because their teachers tended to clarify difficult concepts more effectively to the learners. Also in support of the present findings, is a study by Hamid (2009) who found out that learners who had received private lessons attained higher grades than their counterparts who had not received private lessons. Further to these studies, Bray (1999) established that extensive use of extra lessons paved way for better performance. A number of other studies elsewhere, have also shown that extra lessons paved way for better performance, be it in secondary or primary school (Howrie, 1999; Mogari et al., 2009). Other studies showed that there were positive effects of extra lessons on subjects such as Mathematics (Jacob \& Lefgren, 2002). In Kenya, Mboi and Nyambedha (2013) establish that extra lessons were beneficial in propping up learners` academic performance.

Concurring with the present findings, Suleman and Hussain (2013) in Pakistan found out that there was significant positive effect of private tuition on the academic achievement of secondary school learners in mathematics because of the special attention given to each learner by the teacher. There were positive academic effects of extra lessons on subjects such as Mathematics as established by Jacob and Lefgren (2002). Sharing the results, Zhang (2011) establishes that there was a positive correlation 
between private tutoring and academic achievement mostly as a result of one-on-one interaction for the low performing urban learners.

The findings of the present study do not seem to agree with a number of findings elsewhere. For example, Byun and Park (2012) concluded that private tutoring had no significant effect on SAT performance for all racial groups in America. Similarly, Smyth (2009) established that there was no significant difference in grades between those who intensively got involved and those who were less involved in extra lessons. In support, in Singapore, (Cheo \& Quah, 2005) established that time spend on private tutorials with the Grade 8 learners impacted negatively on the academic attainment of learners. The same findings were established by Ha and Harpham (2005) in Vietnam in a study on extra classes and their outcome in primary schools. Also in contrast to the present study, Suryadarma et al. (2006), in a study on improving studentes performance in primary schools in Indonesia, found out that private tutoring had no impact on Mathematics and dictation scores of Grade 4 pupils. Worse off, a study by Dang and Rogers (2008) established a negative impact of private tutoring in some countries. The differences could be attributed to the view that most studies revealing a negative, and no significant impact, were carried out in the primary schools where the learners could be fatigued because of their age and may not be as resilient as those in the secondary schools to withstand exhaustion, to the extent of not benefiting at all from the extra lessons (Ha \& Harpham, 2005; Suryadarma et al., 2006). The same results were obtained by Deke, Dragoset, Bogen, and Gill (2012) who establish that there was no significant impact of the SES initiative (an equivalent of extra lessons), in Math or reading test scores, of the learners who were enrolled in the programme.

\subsection{Assisting Learners in Passing Examinations}

Tied to the role of improving learner academic achievement, is the view that extra lessons are being used to help learners pass examinations. These examinations include both school and national examinations. Learners were being drilled into how to pass examinations so that they could pass examinations. For that reason, learners get psyched up for the examinations as they received guidance and counselling on how to go about the examinations (Hockenbury \& Hockenbury, 2003).

Participant Mr. Tsuro`s remarks are a typical case. Expressing his pleasure in the positive role played by extra lessons, he revealed that extra lessons in improving the prospects of the learners passing examinations. Mr. Tsuro opined as follows:

So I think they are benefitting quite well.... evidence that we have is quite handy because as we offer these extra lessons, basically we are equipping these learners with examination techniques because our thrust is just to hammer on those things that are bound to help these learners to undertake examinations.

From the excerpt, extra lessons teachers focus a lot on examinations as shown in the phrase "basically we are equipping these learners with examination techniques". The main aim of extra lessons, as reflected in the views, is to give a lot of attention to examination. The phrase "our thrust is just to hammer on those things that are bound to help these learners to undertake examinations" shows that emphasis during the extra lessons, is on passing examinations. Therefore, learners who attend extra lessons tend do well since they are drilled on how to pass examinations through the thorough revision of examination questions and equipping the learners with examination techniques.

Report books for local examinations produced at the end of the term were made available to the

International Journal of Educational Studies

Vol. 2, No.3, pp. 136-150

2019

DOI: $10.53935 / 2641-533 x . v 2 i 3.116$

Funding: This study received no specific financial support.

Article History:

Received: 2 August 2019

Revised: 9 September 2019

Accepted: 11 October 2019

Published: 8 November 2019

(C) 2019 by the authors; licensee Academic

Publishing Group researcher. Three of the learners whose report books were perused, were improving in terms of grades attained. For example, one participant learner, Ben, as indicated in the academic record book for three consecutive school terms showed quite some remarkable progress. The progress is commented upon by the class teacher who indicated "Generally, the students is doing well in all subjects and is encouraged to keep up the good work". The learner had been attaining average scores in early stages of his studies but achievement rose to above satisfactory in the subsequent school terms. Qualitative remarks provided by various teachers in various subjects indicated that the learner was excelling in all the subjects. The various teacher indicated different remarks but the remark "student has improved" in the subject, appeared more than twice signaling that there was indeed some improvement in performance. 
All this is evident that private lessons assist learners to pass examinations. In agreement with the results of the present study, findings by Barrow and Lochan (2012), Mboi and Nyambedha (2013) testify to the fact that extra tuition make learners pass examinations and this in turn enable them to progress to the next grade level in the school system. Like the findings by Bray and Lykins (2012) in Sri Lanka, the need to pass examinations were the major drivers of extra lessons among the participants in their study. According to Bray and Lykins (2012), 68\% of the respondents indicated that they attended extra lessons because of the need to pass examinations. This resonates well with the views provided by all the groups of participants in the study, who are teachers, parents, learners and the school inspectors, that extra lessons were paving way for learners to pass their examinations (Nath, 2016).

However, on how those not attending extra lessons were performing in the formal system in relation to those attending the extra lessons, some participants were not forthcoming. Mr. Owens indicated that it all depended on the natural intelligence of the learner. He had only noticed better performance on those that attend extra lessons. Otherwise, he had not seen the difference on those who were not part of the extra lessons because it was quite difficult to ascertain. This was also substantiated by the researcher in some of the exercise books that were submitted for scrutiny. In a few cases, exercise books for those who attended extra lessons reflected that they were not making any remarkable progress while some who were not attending were improving academically. A study by Lee and Lee (2004) in Korea, on the effects of pre-class private lessons on middle and high school learners, concurs with these findings when it established that the extra lessons had no short or long term effects on the learner"s performance. It was therefore, probably out of the learners' innate ability that there was improvement in their academic attainment. However, strong evidence has been established in a lot of studies, linking academic achievement to attendance in extra lessons (Banerjee et al., 2007; Bray, 1999; Hamid, 2009; Howrie, 1999; Mogari et al., 2009) . All these studies found out that learners who had received private lessons had the chance of attaining higher grades than their counterparts who had not received private lessons. There were positive effects of extra lessons on subjects such as Mathematics (Jacob \& Lefgren, 2002). Private lessons, through a remedial education programme in India, increased the average scores in a test for learners who had been involved in the treatment group (Banerjee et al., 2007).

\subsection{Dealing with Learner Challenges on Individual Basis}

Extra lessons have been ideal in dealing with learners" challenges on a one-on-one basis. As expressed by the majority of the participants, extra lessons assist in dealing with learner challenges on a one-to-one basis. With the teacher-pupil ratios as high as 1:65 in most urban day high density secondary schools, it is very plausible that learners and their parents find it very appropriate to engage teachers for extra lessons (Tokwe, 2010). A typical example of the quest for a one-on-one interaction by the teachers is contained in the following excerpt in which learner participant Ben had this to say:

At the extra lessons, teachers use the one-to-one approach quite well if you ask unlike at school where you will be more than 50 . The teacher just focuses on those who would have grasped the concepts. Those are he or she focuses on.

From the excerpt, the phrase "one-to-one approach" shows that extra lessons are attractive to learners, teachers and parents. The formal school classroom is overcrowded as shown as shown by phrase "you will be more than 50". The scenario where there a lot of learners crammed in one classroom tends to put off the teacher who then resorts to ignore the slow learners reflected by the phrase "focuses on those who would have grasped the concepts". This disadvantages the other learners. School inspector Mr. Mhofu (not his real name), also shares the same views in the following excerpt:

The teacher becomes more motivated and is able to do more. The second option, is the learner becomes a privileged client who is accorded respect during lessons. The tutor or teacher becomes more sensitive to client needs, flexible, with a flexible timetable. The content is tailor made to suit the client who is the learner who attends the extra lessons.

Thus the teacher puts more effort on a one-on-one basis as shown by the phrase "becomes more motivated and is able to do more". This cements the findings from participants in the study by Nath (2016) who argues that what the learners failed to understand from the formal class, they got help from 
the tutor during private lessons as their tutors were more motivated and friendlier than their teachers in the formal system. In the one-on-one situation, a lot of respect is offered to the learner, who has his or her rights as seen in the phrase "becomes a privileged client", which does not normally happen in the formal classroom situation, where the teacher is usually heavy handed and does not listen to the learners. the teacher, during extra lessons, makes sure lessons are suitable for specific learners as highlighted in the phrase "content is tailor made to suit the client".

Most of the times, teachers have complained about their working conditions, through their staff associations. Among the grievances, has been the complaint that teachers are overwhelmed by the learner numbers that they are supposed to handle in a particular lesson (Jinga \& Ganga, 2012). However, during extra lessons, learners are free to consult on areas of difficulties and since extra lessons provide one-to-one assistance as "become privileged clients". Learners get personal assistance as the teachers get to know the individual weaknesses of the few learners under their custody and timeously provide remediation as opposed to the situation in the formal classroom situation. In support of the view that extra lessons have become a panacea for handling large student numbers in the formal class rooms, the following excerpt from an interview with participant teacher T2, Mr. James (not his real name) who says:

Learners are benefitting a lot because in classroom situation, there are very large numbers but when it comes to extra lessons, there are few numbers or individuals. This is an opportunity for students to be on a one-on-one basis with teachers so that they are in a position to understand all concepts they are taught. They are not able to ask during the normal classroom routine where there are so many students.

Parts of the excerpt indicate that there "are few numbers or individuals" during extra lessons. This is unlike the formal school situation where learners are overcrowded to the detriment of effective instructional processes as symbolised by the phrase "there are very large numbers". One key feature of extra lessons, the one-on-one interaction between the teacher and the learner, makes it possible for extra lessons to provide a platform for learners to understand concepts better than in the formal classroom situation as they can ask questions, which is not possible in the formal classroom. Learners do not have the opportunity to ask in the formal classroom because of the large numbers as signified by the phrase "where there are so many students". It would therefore, imply that because of the obtaining situation during the extra lessons, opportunity for understanding is highly unlikely to be achievable because learners are exposed to unconducive learning environments as reflected by high teacher-pupil ratios. This is captured in one of the excerpts where Moxon remarks "because in the formal class we were more than 50 and in the extra lessons class, we could be less than 15". This implies the large numbers scuttle meaning learning and learners find it profitable to attend extra lessons.

\subsection{Remediation}

Extra lessons come in a form of remediation for learners who fail to grasp concepts during the normal and formal school hours. this is reflected in a number of excerpts by different participants. For example, as Mr. James puts it:

The role of extra lessons is simply to ensure that those students who would not have done well in class, during the normal school routines, obtain extra guidance by teachers in order that they perfect in areas that they would not have done well on a one-on-one basis or as few individuals.

International Journal of Educational Studies

Vol. 2, No.3, pp. 136-150

2019

DOI: $10.53935 / 2641-533 x . v 2 i 3.116$

Funding: This study received no specific

financial support.

Article History:

Received: 2 August 2019

Revised: 9 September 2019

Accepted: 11 October 2019

Published: 8 November 2019

(c) 2019 by the authors: licensee Academic

Publishing Group

From the above assertions by the participant, extra lessons are mostly meant as a platform to rectify learners' deficiencies in the formal class. This is shown in the usage of the phrase" simply to ensure that those students who would not have done well in class". In the process of remediation, learners are provided the opportunity to rectify some areas and become more proficient in issues that could be grey areas during the formal classroom situation as signified by the phrase "perfect in areas that they would not have done well. Such opportunities are made possible because learner numbers are very manageable and this is reflected in "on a one-on-one basis or as few individuals". The issue of providing assistance to small groups of learners continues to come out in the different narratives and given this arrangement, work and progress are closely monitored and adequate feedback given than was the case in a normal 
classroom situation where there were large numbers of learners in a single class, in the formal system. The evidence gathered from learner participants, and substantiated through perusal of attendance registers at the school, shows that most classes had in excess of 60 learners thereby making it difficult for the teacher to provide meaningful remediation let alone effective teaching and individual attention to the learners (Jinga \& Ganga, 2012). Hence, extra lessons afford learners the opportunity to for remediation on areas of difficulty in their subjects since they have more face to face time with educators as well as being fewer in numbers.

\subsection{Enhancing Slow Learners' Achievement and Sustaining Gifted Learners'Academic Levels Through Extension Work to Cover the Syllabus}

Extra lessons are playing a role in propping up slow learners who are finding it difficult to cope in the mainstream classes (Nath, 2016). At the same time, the extra lessons are assisting in the provision of extension work to gifted learners. This is captured in following excerpt in which one of the teachers, Mr. Sango (not his real name) indicates that:

...by and large, especially for slow learners, I think they help them in catching up with areas the mainstream doesn"t cater for. However, having said that, the benefits are divided among slow and fast learners. For slow learners, extra lessons have provided remedial work to catch up. Extension work has been provided to fast learners for faster syllabus coverage.

In the excerpt, extra lessons cater, to a large extent, for slow learners as indicated by "especially for slow learners". it is explicit for the excerpt that extra lessons are for slow learners as a means of remediation as indicated in the phrase "for slow learners, extra lessons have provided remedial work". Those lagging behind are made to catch up with the fast learners. As for the fast learners, extra lessons are provided for in order to cover the syllabus as indicated in the sentence "Extension work has been provided to fast learners for faster syllabus coverage". In support of these findings, Deke et al. (2012) establish that extra lessons were meant to cater for less gifted and underprivileged learners. Though in their findings, Deke et al. (2012) remark that the extra tuition programme was failing to deliver in terms of providing significant results in the identified learners, findings in the present study seem to suggest that learners who were lagging behind were catching up with the fast learners. This is indicated in the phrase in the phrase "provided remedial work to catch up". Another study by Baker et al. (2001) establish that extra lessons were adopted as an enrichment strategy for those lagging behind in different subjects. Baker et al. (2001) further established that extra lessons were commonly used by low performing Mathematics learners, who felt their low performance could be remedied more than high Mathematics performers who did not the extra lessons at all, thereby giving support to the findings of the current study in concurrence with the excerpt when the participant says "especially for slow learners".

While remediation is for the slow low learners, fast learners who attend extra lessons receive extension work, in the excerpt, it would appear the average learner is not a candidate for the extra lessons. The exclusion of the average learners could result in them losing out extensively because coverage of the syllabus in the formal is often hindered by the large number of activities in the schools, which might include sporting activities. Coupled with the exclusion, the urban day high density schools are "hot sitting schools" and time is barely adequate for all the activities.

International Journal of Educational Studies

Vol. 2, No.3, pp. 136-150

2019

DOI: $10.53935 / 2641-533 x . v 2 i 3.116$

Funding: This study received no specific financial support.

Article History:

Received: 2 August 2019

Revised: 9 September 2019

Accepted: 11 October 2019

Published: 8 November 2019

(C) 2019 by the authors; licensee Academic

Publishing Group

\subsection{Helping Learners in Getting Admission into Institutions of Higher Learning}

Extra lessons are also playing a pivotal role in as far as are assisting learners in the urban high density secondary schools be admitted into institutions of higher learning, locally and abroad. For example, Mr. James` conviction is that extra lessons have positive through churning academically gifted people who would have achieved higher grades who would be in a position to attend institutions of higher learning such as colleges and universities. The following excerpt helps sum up his views: After extra lessons, they are in a position to obtain good grades and have a chance to go for tertiary institutions for higher learning and also they can be in a position to be engaged in employment. 
The phrase "have a chance to go for tertiary institutions for higher learning demonstrates" that learners get admitted into colleges and universities only after getting good passes. The good passes are obtained in the event that learners attend extra lessons as shown in the phrase "After extra lessons". In support of the present findings, a study by Silova and Bray (2006) establish that over 70\% of the students enrolled in the universities in Azerbaijan, Georgia, Mongolia and Lithuania indicated that they had undergone extra lessons in their final year in secondary school. The same findings were established in a study in Ireland by Smyth (2009) which established that those who had taken grinds (a form of extra lessons) in their last year of study at school were more than twice likely to enter institutions of higher learning than those who had not.

\section{Conclusion}

While extra lessons have been of concern to the various stakeholders, they have been very useful in assisting learners improve their academic achievement. One of the main findings of this study is that extra lessons are being used by learners in urban day high density secondary schools to improve their academic achievement. As depicted in the interview excerpts, participants extolled the positive role played by extra lessons in propping learner academic achievement. Tied to the role of improving learner academic achievement, is the view that extra lessons are being used to help learners pass examinations. These examinations include both school and national examinations. Learners were being drilled into how to pass examinations so that they could pass examinations. Extra lessons have also been ideal in dealing with learners" challenges on a one-on-one basis and come in as a form of remediation for learners who fail to grasp concepts during the normal and formal school hour. On one hand, extra lessons are playing a role in propping up slow learners who are finding it difficult to cope in the mainstream classes and on the other, they are assisting in the provision of extension work to gifted learners. Extra lessons are also playing a pivotal role in as far as are assisting learners in the urban high density secondary schools be admitted into institutions of higher learning, locally and abroad. While literature reviewed seem to suggest that in some cases, there could be no significant benefit to some learning in engaging in extra lessons, Zimbabwean educational stakeholders do concur that they have a very positive role to play among learners in secondary schools.

\section{Recommendations}

The following recommendations are proposed for the different categories of stakeholders:

- Parents and guardians need to take extra lessons seriously as they pave way for improved pass rates among learners.

- Due to limited time in the mainstream system, extra lessons could be used make up for the time limitations especially in the urban day high density secondary schools where there is hot sitting or double sessioning.

- While extra lessons have proved to be potent in propping up learner achievement, there is need to monitor the learners as they go away for the extra lessons to find out if in deed they are benefitting from them.

- Learners need to take into account they should not wait for teachers to do virtually everything for them but rather use extra lessons for guidance on how they go about certain activities rather than leave everything for the extra lessons teacher.

- While extra lessons are a worthwhile activity, learners should be able to do most the activities through learner centred approaches, under the guidance of the teachers.

International Journal of Educational which could also be used as a basis for future manpower base by the Government of Zimbabwe.

\section{References}

Baker, D. P., Akiba, M., Le Tendre, G. K., \& Wiseman, A. W. (2001). Worldwide shadow education: Outside- school learning, institutional quality of school and cross-national mathematics achievement. Educational Evaluation and Policy Analysis, 23(1), 1-17. 
Baker, D. P., Akiba, M., Le Tendre, G. K., \& Wiseman, A. W. (2011). Worldwide shadow education: Outside- school learning, institutional quality of school and cross-national mathematics achievement. Educational Evaluation and Policy Analysis, 23(1), 1-17.

Baker, D. P., \& Le Tendre, G. K. (2005). National differences, global similarities: World culture and the future of schooling. Stanford: Stanford University Press.

Banerjee, A., Cole, S., Duflo, B., \& Linden, L. (2007). Remedying education: Evidence from two randomised experiments in India. Quarterly Journal of Economics, 22(12), 55-64.

Barrow, D. A., \& Lochan, S. N. (2012). Supplementary tutoring in Trinidad and Tobago: Some implications for policy making. International Review of Education, 58(3), 405-422.

Baxter, P., \& Jack, S. (2008). Qualitative case study methodology: Study design and implementation for novice researchers. The Qualitative Report, 13(4), 544-559.

Bernstein, D. A. (2011). Essentials of psychology. Belmont, CA: Wadsworth.

Bewu, C. (2013). Extra tuition as extra lessons in Zimbabwe. Government Printers: Harare.

Bray, M. (1999). The shadow education system: Private tutoring and its implications for planners. Paris: UNESCO, International Institute for Educational Planning.

Bray, M. (2001). Confronting the shadow education system: What government policy for what private tutoring? (2nd ed.). Paris: UNESCO, International Institute for Educational Planning.

Bray, M. (2003). Home learning and the educational marketplace. Oxford Review of Education, 30(2), 287-303.

Bray, M. (2005). Adverse effects of private supplementary tutoring: Dimensions, implications, and government responses. Paris: UNESCO, International Institute for Education Planning.

Bray, M. (2009). Confronting the shadow education system: What government policy for what private tutoring? Paris: International Institute for Educational Planning.

Bray, M. (2011). The shadow education system: Private tutoring and its implications for planners. Paris: UNESCO.

Bray, M. (2013). The shadow education system: Private tutoring and its implications for planners. Paris: UNESCO.

Bray, M. (2015). Demand for private supplementary tutoring: Conceptual considerations, and socio-economic patterns in Hong Kong. Economics of Education Review, 22(6), 11-20.

Bray, M., \& Lykins, C. (2012). Shadow education: Private supplementary tutoring and its implications for policy makers in Asia." In CERC Monograph Series in Comparative and International Education and Development No. 9. Asia Development Bank: Mandaluyong City.

Brink, H. (2006). Fundamentals of research methodology for health care professionals. Ltd: Cape Town: Juta and Co.

Buchmann, C. (2002). Shadow education: Theory, analysis and future directions: A rejoinder. Oxford: Oxford University Press.

Byun, S., \& Park, H. (2012). The academic success of east Asian American Youth: The role of shadow education. Sociology of Education, 85(1), $40-60$.

Cheo, R., \& Quah, E. (2005). Mothers, maids and tutors: An empirical evaluation of their effect on children"es academic grades in Singapore. Education Economics, 13(3), 269-285.

Cherry, K. (2016). The incentive theory of motivation: Are actions motivated by a desire for rewards? Milton Keynes: Open University Press.

Creswell, J. W. (2012). Research design: Qualitative, quantitative, and mixed methods approaches (2nd ed.). Thousand Oaks, CA: Sage Publications.

Dang. (2007b). The determinants and impacts of private tutoring classes in Vietnam. Economics of Education Review, 26(6), 684-699.

Dang, \& Rogers, F. H. (2008). The growing phenomenon of private tutoring: Does it deepen human capital, widen inequalities, or waste of resources? The World Bank Research Observer, 23(2), 262-200.

Davies, S., \& Aurini, J. (2016). The franchising of private tutoring: A view from Canada. The Phi Delta Kappan, 88(2), 123-128.

Deke, J., Dragoset, L., Bogen, K., \& Gill, B. (2012). Impacts of title I supplemental educational services on student achievement (NCEE 2012-4053). National Centre for Education Evaluation and Regional Assistance, Institute of Education Sciences, U.S. Department of Education. Washington, DC.

Dina, W. (2012). The research design maze: Understanding paradigms, cases, methods and methodologies. Journal of Applied Management Accounting Research, 10(1), 69-80.

Flick, U. (2011). Introduction to qualitative research. Los Angelessw: Sage Publications.

Ha, T. T., \& Harpham, T. (2005). Primary education in vietnam: Extra classes and outcome. International Education Journal, 6(5), 626-634.

Hallak, J., \& Poisson, M. (2007). Corrupt schools, corrupt universities: What can be done? : International Institute for Educational Planning. Paris: UNESCO.

Hamid, M. O. (2009). Private tutoring in english for secondary school students in Bangladesh. TESOL Quarterly, 43(2), $281-308$.

Hessie-Biber, S. N., \& Leavy, P. (2006). The practice of qualitative research. London: Sage Publications.

Hockenbury, D. H., \& Hockenbury, S. E. (2003). Psychology. New York: Worth Publishers.

Howrie, S. (1999). Third international mathematics and science study report. Cape Town: HSCR Press.

Ireson, J., \& Rushforth, K. (2005). Evaluating the impact of individual tutoring on gsce attainment. Paper presented at the In Paper Presented at the British Educational Research Association Annual Conference, University of Glamorgan.

Jacob, B., \& Lefgren, L. (2002). Remedial education and student achievement: A regression-discontinuity analysis. Working Paper 8918. National Bureau of Economic Research: Massachusetts.

Jacob, B., \& Lefgren, L. (2004). Remedial education and student achievement: A regression-discontinuity analysis. Working Paper 8918. National Bureau of Economic Research (NBER): Massachusetts.

Jinga, N., \& Ganga, E. (2012). Effects of holiday lessons and financial pressures on low -income families and households in Masvingo. Zimbabwe Journal of Emerging Trends in Educational Research and Policy Studies, 2(6), 465-470. 
Johnson, B., \& Christensen, L. (2012). Educational research. Quantitative, qualitative and mixed approaches. Sage Publications. California: Los Angeles.

Lee. (2002). The best intentions: Meritocratic selection to higher education and development of shadow education in Korea. New York: Routledge.

Lee, \& Lee, K. (2004). Korean education fever and private tutoring. Korean Educational Development Institute Journal of Educational Policy, 2(1), 98-108.

Mboi, P. A., \& Nyambedha, E. O. (2013). Implication of extra tuition in primary schools on pupilse social life in kisumu municipality. Western Kenya International Journal of Education and Research, 1(5), 1-12.

Mischo, C., \& Ludwig, H. (2002). Expansion and effectiveness of private tutoring. European Journal of Psychology of Education, 17(3), 263-273.

Mogari, D., Coetzee, H., \& Maritz, R. (2009). Investigating the status of supplementary tuition in the teaching and learning of mathematics. Pythagoras, 69(5), 36-45.

Moloi, M. Q. (2001). Mathematics achievement in South Africa: A comparison of the official curriculum with pupil performance in the sacmeq southern african consortium for monitoring educational quality ii project. Retrieved from: www.jet.org.za/.

Nath, S. R. (2016). Private supplementary tutoring among primary students in Bangladesh. BRAC Report Published by Research Gate Available.

Neuman, W. L. (2014). Basics of social research: Qualitative and quantitative approaches (7th ed.). Essex: Pearson Education Limited.

Paviot, L., Heinshohn, N., \& Korkman, J. (2008). Extra tuition in southern and eastern Africa. Coverage, growth, and linkages with pupil achievement. International Journal of Educational Development, 28(2), 149-160.

Reddy, V., Berkowitz, R., \& Mji, A. (2005). Supplementary tuition in mathematics and science: An evaluation of the usefulness of different types of supplementary tuition programmes. Pretoria: Human Sciences Research Council.

Russell, N. U. (2002). The Kumon approach to teaching and learning. Cambridge: Cambridge University Press.

Silova, I., \& Bray, M. (2006). The hidden market place: Private tutoring in the former socialist countries. New York: Open Society Institute.

Skinner, B. F. (1950). Are theories of learning necessary? Psychological Review, 57(5), 193-216.

Smyth, E. (2009). Buying your way into college? Private tuition and the transition to higher education in Ireland. Oxford Review of Education, 35(4), 1-22.

Sohn, H., Donghwan, L., Sunhwa, J., \& Tae, K. K. (2010). Longitudinal relationship among private tutoring, student-parent conversation, and student achievement. KEDI Journal of Educational Policy, 7(1), 23-41.

Southgate, D. E. (2009). Determinants of shadow education: A cross-national analysis. Retrieved from: https://etd.ohiolink.edu/!etd.send_file?accession=osu1259703574.

Suleman, Q., \& Hussain, I. (2013). Effects of private tuition on the academic achievement of secondary school students in subject of mathematics in Kohat division, Pakistan. International Journal of Learning and Development, 3(3), 253-269.

Suryadarma, D., Suryahadi, A., Sumarto, S., \& Rogerset, F. H. (2006). Improving student performance in public primary schools in developing countries: Evidence from Indonesia. Education Economics, 14(4), 401-429.

Tokwe, S. (2010). Extra cash lessons. The sunday mail newspaper. Zimpapers: Harare.

Yasmeen, B. (2009). Spreading private tuitions epidemic in schools. Journal of Educational Excellence, 4(2), 21-25.

Young, P. T. (1936). Motivation of behaviour: The fundamental determinants of human and animal activity. New York: John Wiley and Sons.

Zhang, Y. (2011). The determinants of national college entrance exam performance in (People's Republic of) China: With an analysis of private tutoring. Columbia University: PhD Dissertation.

International Journal of Educational

Studies

Vol. 2, No.3, pp. 136-150

2019

DOI: $10.53935 / 2641-533 x . v 2 i 3.116$

Funding: This study received no specific

financial support.

Article History:

Received: 2 August 2019

Revised: 9 September 2019

Accepted: 11 October 2019

Published: 8 November 2019

(C) 2019 by the authors; licensee Academic

Publishing Group 